technique to detect nucleoprotein (NP) antigens and RT-PCR were positive for pandemic H1N1 influenza. The virus antigen was also detected by flow cytometry using monoclonal antibody specific for NP labeled with fluorescein isothiocyanate (FITC). Interestingly, most of positive cells were CD14+ cells and the amounts of positive cells were $10 \%$ of total marrow cells. His immunological profiles were normal.

Conclusion This infant demonstrated the evidence of disseminated pandemic H1N1 influenza prior having pneumonic symptoms. Infant is more susceptible to have disseminated manifestation and can present initially as clinical sepsis.

\section{ASPERGILLUS NIGER: AN UNUSUAL CAUSE OF INVASIVE PULMONARY ASPERGILLOSIS}

doi:10.1136/archdischild-2012-302724.0522

S Hammami, S Haddad, K Lajmi, N Bel Hadj Brahim, L Ghédira, C Ben Meriem, MN Guediche. Paediatric Department, Faculty of Medicine - Monastir University, Monastir, Tunisia

Objective Report two cases of chronic granulomatous disease presenting with uncommon cause of invasive pulmonary aspergillosis (IPA).

Methods We report two cases of IPA in two 6-year-old twin girls with a family history of primary immunodeficiency and a personal medical history of recurrent bronchopneumopathy referred to our Pediatric Department in July 2011 for investigations regarding persistent pneumonia and biological inflammatory syndrome. IPA was confirmed by isolating Aspergillus niger from bronchoalveolar lavage and radiology results. Amphotericin B therapy was initiated intravenously for 1 month relayed then by oral Voriconazole for two months. Clinico-biological evolution was favourable. Followup computed tomography showed full regression of the pulmonary infiltrates and the thoracic wall mass after 3 months of antifungal therapy. Investigation for immune deficiency revealed chronic granulomatous disease. Our two patients started then on prophylactic antibiotics with co-trimoxazole. We are currently considering HLA identical bone marrow transplantation for them in a near future.

Conclusion Although is a well recognized clinical entity, invasive disease caused by aspergillus niger is less common when compared to aspergillus fumigatus and other Aspergillus species. These two case reports demonstrate the potentially aggressive nature of aspergillus niger and highlight the importance of looking for an immune deficiency particularly in the case of uncommon infection such as aspergillosis in early childhood.

\section{A CASE REPORT; BRUCELLOSIS TRIGGERING HEMOLYTIC ANEMIA IN GLUCOSE-6-PHOSPHATE DEHYDROGENASE DEFICIENCY}

doi:10.1136/archdischild-2012-302724.0523

${ }^{1} \mathrm{M}$ Özkale, ${ }^{1} Y$ Özkale, ${ }^{2} \mathrm{~A}$ Erbay, ${ }^{1} \mathrm{U}$ Paltacı, ${ }^{3} \mathrm{~S}$ Asilsoy. ${ }^{1}$ Pediatric; ${ }^{2}$ Pediatric Oncology; ${ }^{3}$ Pediatric Allergy, Baskent University, Adana, Turkey

Background and Aims Glucose-6-phosphate dehydrogenase (G6PD) deficiency is the most common red blood cell enzyme deficiency in worldwide. It may lead to acute hemolytic anemia triggered by infection, drugs or broad beans (favism). To the best of our knowledge, this is the second reported case of a Turkish patient with brucellosis triggering hemolytic anemia in glucose-6-phosphate dehydrogenase deficiency.

Case A 5-year-old male was admitted our hospital with malaise, fever, abdominal pain, vomiting, jaundice, and darkening of urinary color of one week duration. There were no intake drug, infectious diseases or favism in patient's history. On physical examination conjunctivae were pale, sclerae were subicteric and the other system examinations were normal. Laboratory examinations revealed leukocyte count of $22800 / \mathrm{mm}^{3}$, hemoglobin of $5.7 \mathrm{~g} / \mathrm{dl}$, platelets of $596000 / \mathrm{mm}^{3}$, total bilirubin:4.3, indirect bilirubin:3.9 mg/dl, lactate dehydrogenase:1440U/1, AST:190IU/L, ALT:181IU/L. The corrected reticulocyte count was $9.3 \%$ and serum haptoglobin level was low $(<10)$. There was hemoglobinuria in the urinary examination. Direct and indirect Coombs tests were negative. The value of G6PD was low $(3.8 \mathrm{IU} / \mathrm{g}$ ) where osmotic fragility was normal. Serum standard tube agglutination (Wright) test for Brucella sp was positive at a titer of $1 / 640$. The patient was treated by rifampicin and gentamicin.

Conclusion We presented this case report to show that acute brucellosis might trigger an acute hemolytic attack in a patient with underlying G6PD deficiency. This is important especially in countries such as Turkey, where brucellosis is endemic and there is a high frequency of G6PD deficiency in the population.

\section{TWO PEDIATRIC CASES OF CEREBRAL VENOUS SINUS THROMBOSIS WITH DIFFERENT PRESENTATIONS}

doi:10.1136/archdischild-2012-302724.0524

'B Kiliçaslan, ${ }^{2} \mathrm{E}$ Erol, ${ }^{3} \mathrm{~N}$ Yazıcı, ${ }^{4} \mathrm{O}$ Alkan. ${ }^{1}$ Department of Pediatrics; ${ }^{2}$ Department of Pediatrics, Division of Child Neurology; ${ }^{3}$ Department of Pediatrics, Division of Child Hematology and Oncology; ' Department of Radiology, Baskent University Hospital, Adana, Turkey

Background and Aims Cerebral Venous Sinus Thrombosis (CVST) is a serious and rare disorder in pediatric patients.

Case reports: Case 1: An 8-year-old girl admitted with left middle ear infection, bilateral sixth cranial nerve palsy and papilledema. The Magnetic Resonance Imaging (MRI) venography showed occlusion of superior and inferior sagittal sinus totally and left sigmoid sinüs parsial.Pansinüsitis, left otitis media and mastoiditis were also determined. Evaluation for thrombophilia and tests for specific predisposing conditions were normal. The patient was treated by third generation cephalosporin, clindamycin, acetazolamide and low-molecular weight heparin after the initial diagnosis.

Case 2: A 12-year-old boy presented with aphasia and lethargy after a week of dental infection. Brain MRI and MRI venography demonstrated thalamic enfarct, thrombosis of deep cortical veins, left transverse and sigmoid sinuses.

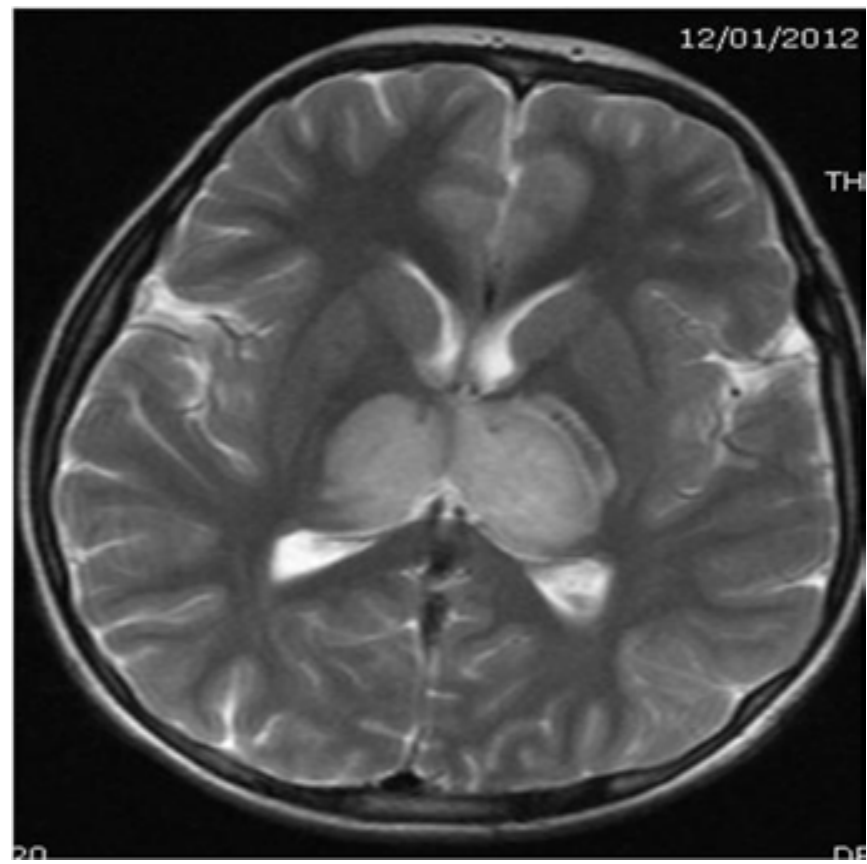

Abstract 524 Figure 1 